\title{
A Doctoral Teaching Program in Engineering
}

\section{Dr. Donald P. Visco Jr., University of Akron}

Donald P. Visco, Jr. is the Dean of the College of Engineering at The University of Akron and Professor of Chemical \& Biomolecular Engineering.

\section{Nidaa Makki}

Dr. Nidaa Makki is an Associate Professor in the LeBron James Family Foundation College of Education at The University of Akron, in the department in Curricular and Instructional Studies. Her work focuses on STEM curriculum integration and science inquiry practices in middle and high school. She is a co-PI on an NSF funded project to investigate the impact of integrating engineering on middle school students' interest and engagement in STEM. She has also received funding to conduct teacher professional development in the areas of engineering education, problem based learning and inquiry instruction.

\section{Ms. Esther R. Wain-Weiss, Universtiy of Akron}




\section{A Doctoral Teaching Program in Engineering at The University of Akron}

\section{Introduction}

As the decades progress, new faculty hires at engineering colleges across the US are being asked to reach different and, often, higher bars on their way to tenure. While this information is anecdotal, it is based on the authors' own experience, as well as in speaking to many others in the field. Note that a thorough assessment is problematic as published tenure requirements often focus on what is to be included or considered in tenure applications, as opposed to levels of achievement. Indeed, some departments and colleges purposefully do not identify levels of achievement and prefer a more holistic and less definitive review of tenure cases. At any rate, the "higher bar" for tenure includes research dollars (or increased amount of the same), even at places where this was not the focus historically.

For new professors with this additional pressure, one of the many areas that often are left behind is the improvement and development of their teaching skills. Indeed, being an adequate teacher (relative to others in the program or college) is regularly the requirement for tenure (via some quantitative measures, such as end-of-semester evaluations). Therefore, one may opine that despite the availability of centers for teaching and learning on many college campuses or the ubiquity of teaching workshops, new faculty in engineering need to spend their available time in their research pursuits to meet the tenure requirements in that area (e.g. external funding dollars, grant submissions, archival publications, mentoring graduate students to degree completion, etc.)

One approach to address this concerning issue is to provide a baseline foundation of engineering education training for potential faculty members during their Ph. D. training. A few of these programs exist already at various schools in the US [1]. For example, the University of Maryland has a "Future Faculty Program" in their College of Engineering that requires program participants to enroll in three one-credit hour training courses, co-teach a course with a faculty mentor and also mentor a less-experienced undergraduate or graduate student. The program currently has 25 students enrolled in the program, though students in Computer Science can participate as well [2].

Another offering available to graduate students is the Georgia Tech "Tech to Teaching" program. Here, students can complete two levels of training: Level 1: Foundations of Teaching and Learning and Level 2: Teaching Capstone. The Level 1 training requires students to complete 10 foundational learning outcomes that are satisfied through workshops, coursework and on-line options. When a student successfully completes Level 1, they can move to the Teaching Capstone portion of the training. In this level, a student can either co-teach or become the instructor of record for a course. The program is managed through the Center for Teaching and Learning on campus [3]. 


\section{The University of Akron Doctoral Teaching Program (DTP)}

At The University of Akron, there was a desire within the college to provide training in teaching for graduate students who had an interest in becoming an engineering professor. Like most institutions across the US, The University of Akron does not currently have a centralized resources and expertise associated with teaching and learning. Thus, any graduate student training in teaching would need to be developed from within. Accordingly, we developed a program that had some of the important elements of those identified in other engineering teacher training programs across the US, but did so in a way that was less resource intensive. Such a model may be replicated by other programs without access to centers for teaching and learning. Our program started in the Fall of 2015.

The stated goal of the program was as follows: "Train interested Ph. D. students in engineering about pedagogy and course delivery, perhaps in preparation for a career as a faculty member." As students would eventually teach classes on their own at the end of the program, the expectation was that this would be for students starting their $4^{\text {th }}$ year as a Ph. D. student. Thus, the student needed to pass their Ph. D. qualifying exam prior to program inclusion. Additionally, the students needed to have good communication skills, which were assessed during an interview.

\section{II.A. DTP Program Requirements}

Program requirements included the following:

- Two year commitment

- Teach up to five class sessions in an undergraduate course during the fall and spring of Year 1. This course would not be a course offered by their Ph. D. advisor

- Attend a bi-weekly workshop in Year 1 on basic engineering education pedagogy, research-based instructional strategies and classroom management approaches

- Attend an off-campus education workshop prior to Year 2

- Teach one undergraduate course each semester (as the instructor of record) in Year 2

Students were given a small, though increasing stipend in both years to encourage commitment and participation.

At the beginning of the summer (prior to Year 1), eligible Ph. D. students would apply to this program and must receive approval to apply by their $\mathrm{Ph}$. $\mathrm{D}$. advisor. No more than one student would be in the program from a faculty member's research group in any given year. Applications included directory information, background information and their $\mathrm{cv}$, as well as 
questions that focused on their interest in the program, career goals and desire to become a faculty member.

All students who applied were interviewed by a team of personnel in the Engineering Dean's Office. The maximum cohort size agreed to prior to the program was six students in any given year. More students than the maximum applied each year. One of the administrators in the Engineering Dean's Office was identified as the "program coordinator".

The courses that the candidates participated in during Year 1 were identified by both the Engineering Dean's Office and the Department Chair of the individual student. The faculty members teaching those courses agreed to participate and were required to discuss with the candidate their own teaching philosophy during the semester. At the end of the semester, they were to provide written feedback to the program on the candidate's performance in the classroom.

\section{II.B DTP Bi-Weekly Workshops}

Year 1 students participated in seven workshops in the Fall and another seven in the spring. Most workshops were focused around topics in the book Teaching Engineering $\left(2^{\text {nd }}\right.$ Edition $)$ by Wankat and Oreovicz [4]. Candidates were required to read sections of the book prior to the workshop and come prepared to discuss at the workshop.

Workshop topics and concepts included:

- Writing course outcomes and objectives

- The case for active learning

- Teaching with technology

- Testing, HW and grading

- Student cheating and classroom discipline

- Teacher and student interactions (role playing)

- Formative and summative course assessments and evaluations

- Learning theories

- Consideration of learning styles in content development

- The ABET accreditation process and you

- FERPA and Title IX: What you are required to know and do

- Starting your class: What to do?

- Typical classroom/course scenarios: Your options and approaches

- The academic job search

The workshops were facilitated mostly by the program coordinator, who has experience in delivering engineering teaching workshops. 


\section{II.C Off-Campus Workshops/Sessions}

To obtain a different perspective than that provided by the textbook and the workshop facilitator, the participants were expected to attend a teaching-related workshop or educational session that was offered off-campus. Different students addressed this requirement in different ways, but each had to gain approval from the program coordinator first. Such approaches included attendance at a session at an ASEE annual or sectional meeting, attendance at an educational session of a disciplinary conference and attendance at a one-day teaching workshop.

\section{II.D DTP Year 2}

At the conclusion of Year 1, candidates are assigned to teach one course in each semester of Year 2. The expectation is that the courses will be one of the courses that they have worked with in Year 1, though this is dictated by need and availability. Additionally, the course assigned in Year 2 will be one for which there are (normally) multiple sections offered so that the candidate can work with a more experienced faculty member, if needed/desired.

During the summer between Year 1 and Year 2, the candidates worked to prepare their course syllabus, including learning objectives. The program coordinator worked with them to review their syllabus and answer any lingering questions.

Each month during Year 2, the candidates met with the program coordinator to discuss challenges in their courses and suggested plans to address those. It is noted that the program coordinator often had to remind the candidates that they had been trained in certain areas to address the challenges they faced. Thus, these monthly meetings during Year 2 proved very important and became a crucial component of the entire program.

At the end of Year 2, the candidates received a college-level certificate for completion of the program. During the Spring and Summer of Year 2, the program coordinator worked with several of the candidates on the teaching philosophy section of their faculty applications, as well as how to effectively discuss their participation in the Doctoral Teaching Program in their cover letters.

\section{Program Impact}

To evaluate the impact of the Doctoral Teaching Program, we conducted an exploratory qualitative study with cohort 1 (the first group of six participants) of the program, after they completed the second-year requirements. A qualitative approach was used given the small number of students in the program, in order to gain an in depth understanding of their 
perceptions of how the program influenced their development as engineering educators. Participants included six doctoral engineering students, five males, and one female.

\section{III.A Data collection methods}

Two methods of data collection were used in this study. An electronic survey was sent to cohort one students in May after completing the second year of the program. The survey included two components: a Likert scale perception of the program survey (see table 1) and open-ended questions on the elements of the program that were most impactful or areas that needed improvement.

To obtain more of an in depth understanding of the students' experience in the program, a semistructured focus group interview was conducted by a researcher not affiliated with the program in a round table conference room located outside the college of engineering, and lasted approximately an hour. All of the doctoral students in cohort one were invited to participate and they all agreed to be interviewed and audio recorded.

The following questions guided the focus group interview:

1. Can you tell me about the impact the program had your preparation and interest for an academic career, with respect to your role as an engineering educator?

2. To what extent are you using the information learned about teaching engineering in your current practice?

3. How prepared do you feel in the teaching aspects of an academic career?

4. To what extent did this program support your job search efforts in relation to teaching engineering?

5. How would you describe a good engineering educator?

6. What were the best aspects of the program?

7. Which aspects need improvement?

8. What, if anything, can be modified in Year 1 to better prepare you for teaching the classes in Year 2?

9. Are you planning on using what you learned in the future?

a. If yes, in what ways?

b. If no, why?

The research was approved by the Institutional Review Board at The University of Akron and participants signed consent forms to participate. The researcher who conducted the interview transcribed the recording using pseudonyms for all participants to protect their privacy. The researcher then conducted a thematic analysis of the data through multiple readings of the transcripts as well as listening to the audio recording. 


\section{III.B Findings}

The results of the survey indicate that participants agreed or strongly agreed that the program prepared them for teaching activities such as writing objectives, using technology, implementing active learning strategies and preparing assessments. One out of six participants responded neutral to the statements on preparing homework, preparing quizzes, adhering to federal guidelines, and writing a teaching statement. Given the small number of participants, the survey results are simply presented as a summary (table 1) as it is difficult to draw conclusions. However, we can infer that participants perceive the program to be successful in preparing them for teaching responsibilities.

Three open ended questions were included in the survey for participants to provide qualitative feedback. When asked about the most impactful elements of the program, four participants specifically mentioned active learning, three listed writing objectives and general teaching skills. Less frequently mentioned were teaching experience (2), ethical issues and discipline (2) and technology (1).

Table 1-Summary of survey results $(\mathrm{N}=6)$

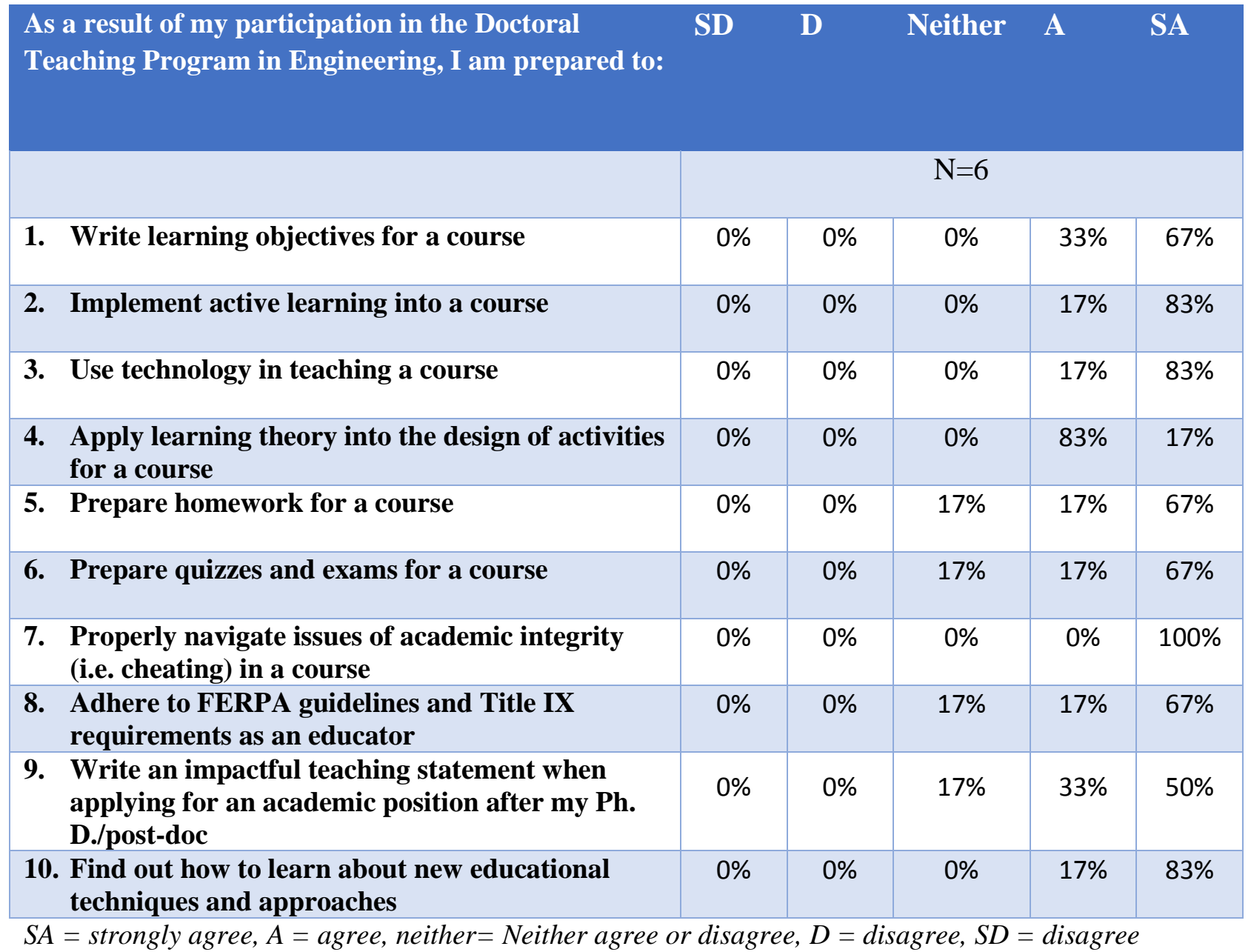


When asked about the areas of the program that can be improved, four participants listed areas such as having more active learning opportunities during the first year, getting feedback from the program coordinator through formal in-class evaluations and receiving training on how to design online courses.

Six participants $(100 \%)$ indicated that they would recommend the program to other students. In explaining their choice, the responses included the importance of the teaching experience for those interested in academic positions as the program prepares them for teaching responsibilities.

The results from the survey were corroborated by the focus group interview results. The following themes emerged from the interview.

\section{III.B.1 Change in attitudes regarding teaching}

Several participants discussed that the program changed their thinking about what it means to be a teacher. Specifically, they highlighted how the program introduced them to active learning strategies. They mentioned that they were not aware of active learning strategies before this program. This was an area that the participants elaborated on and felt that it was a major change in their perceptions. Below are sample quotations from student responses that illustrate this point.

"Before the program, I taught 4-5 days when my advisor was absent. Before the program, teaching was standing in front of class, but in this class, we learned techniques about active learning..."

"I think [good teaching] is a combination of the right attitudes and having the skills; having a right attitude to approach the class from student centered... thinking about your students and adapting to them."

"Before the program, I didn't know about difference between active learning and passive learning..."

"Active learning we have in our back pocket now"

It is interesting to note that as a result of this program, the participants began evaluating faculty in their departments in terms of their use of active learning strategies. One participant commented on the need to expand the program to faculty members and not only doctoral students to be able to make a significant change in teaching quality. It is plausible to infer that having the exposure to active learning strategies can prime future faculty members to pursue methods to improve their teaching and, possibly, be advocates for this at their first academic position. 


\section{III.B.2 Increased skills in teaching}

All participants agreed that this program made them more prepared for the teaching aspect of an academic career. Specifically, they highlighted the following areas that they learned about:

- How to get feedback from students about their understanding

- How to improve student retention

- Using technology in teaching

- Knowledge of what works and what doesn't in the classroom

- How to write learning objectives; building class lecture around key learning objectives; focusing teaching on learning outcomes (as opposed to covering content).

- How to prepare for classes

- Legal issues such as: confidentiality of student info (FERPA), attention to diversity (race/sexual orientation). This was mentioned as especially important for international students who are not familiar with these considerations in the US.

It is noted that one student who is not pursuing an academic career stated that the program did not change their career plans, but recognized the value of the program in improving teaching ability.

\section{III.B.3 Increased Confidence}

The other area where this program impacted the students was in their confidence in their teaching skills. For example, having gone through the program, one person mentioned that they are more efficient at managing their time, because they are comfortable with the teaching aspect, so they can devote more time to research. Another person mentioned that they know how to plan for their course (the steps for teaching a course, what materials to prepare, etc.). This theme is illustrated in the following student quotes:

"Confidence that we develop over time... If you teach a class a second time you become more confident... And I think that's a good thing no matter how skilled you are; to have your confidence."

"Teaching is more focused, more organized preparation ... that I can explain in any interview or any place... definitely I feel more prepared"

The increase in confidence was also linked to the increase in teaching skills. One student emphasized that having the right attitude is one thing, but having the tools/skills to be effective is what's important, which is what the program provided.

\section{Cohort 1 Placement}


At the end of the program, three students also graduated with their $\mathrm{Ph}$. D. and three students continued towards finishing their Ph. D. Of the three students who graduated, two took academic positions and one took a position in industry. It is noted, anecdotally, that an institution that hired one of the Doctoral Teaching Program candidates heard about the program during the interview and now wants to start a similar program at their institution.

\section{Conclusion}

The results of this study highlight that the doctoral teaching program used was effective in increasing the participants' knowledge, skills, and confidence as it relates to teaching engineering. While the number of students included was small, we were able to document the elements of the program that were successful in providing a positive experience for doctoral engineering students, specifically in exposing them to active learning, and providing opportunities to practice teaching and receive feedback.

\section{References}

[1] D. Visco and D. Schaefer, Training Engineering Faculty to be Educators: History, Motivations and a Comparison of US and International Systems Paper presented at 2015 ASEE Annual Conference \& Exposition, Seattle, Washington. 10.18260/p.24932

[2] University of Maryland, Clark School of Engineering, Future Faculty Program https://eng.umd.edu/future-faculty-program (accessed 2/4/2018)

[3] Georgia Institute of Technology: Tech to Teach, http://www.cetl.gatech.edu/content/techteaching-0, (accessed 2/4/2018)

[4] P. Wankat and F. Oreovicz, Teaching Engineering ( $2^{\text {nd }}$ Edition). West Lafayette, IN: Purdue University Press, 2015. 